\title{
The Current Situation and Enlightenment of Social Entrepreneurship Education Research in China
}

\section{Linghui Gao}

School of Journalism and Communications, Shanghai International Studies University, Shanghai, China

\section{Email address: \\ 772036165@qq.com}

\section{To cite this article:}

Linghui Gao. The Current Situation and Enlightenment of Social Entrepreneurship Education Research in China. Science Innovation. Vol. 5, No. 5, 2017, pp. 313-317. doi: 10.11648/j.si.20170505.23

Received: July 1, 2017; Accepted: July 20, 2017; Published: August 16, 2017

\begin{abstract}
Social entrepreneurship and its education has a long history in Europe and America, and it is conducive to promoting the reform of entrepreneurship education, cultivating the correct values of entrepreneurship, guiding attention and solving social problems. In the background of encouraging innovation and entrepreneurship, entrepreneurship education has been vigorously developing in China, social entrepreneurship education is entering into people's eye with the rapid pace, and as a new form of social activities are increasingly concerned by the society. Based on the analysis of nearly ten years of academic research on social entrepreneurship education, this article used the content analysis method to get a deep analysis in four aspects: the literature quantity distribution, periodical distribution, research level and research contents, and divided the research contents of the Social Entrepreneurship Education into four categories: theoretical research, specific application research, talents cultivation, curriculum development. Then put forward to increase the depth of research on the theory of social entrepreneurship education, enrich the research field of social entrepreneurship education, and promote the construction of a comprehensive curriculum system of social entrepreneurship education, and finally hope to promote the further development and improvement of the Social Entrepreneurship Education in China.
\end{abstract}

Keywords: Social Entrepreneurship Education, Current Situation, Enlightenment, Content Analysis Method

\section{中国公益创业教育研究现状及启示}

高玲慧

新闻传播学院, 上海外国语大学, 上海, 中国

邮箱

772036165@qq.com

摘要：公益创业及其教育在欧美国家由来已久, 它有利于推进创业教育改革、培养正确的创业价值观、引导关注和解 决社会问题。而在双创背景下，中国创新创业教育得到大力发展，公益创业教育正以迅猛的态势进入人们的视野中， 作为一种新兴的社会活动形式正日益受到社会关注。文章通过对近十年来对公益创业教育进行研究的学术论文进行研 究分析, 随后采用内容分析法从文献数量分布、期刊分布、研究层次和研究内容四个方面进行了详细的分析, 并把目 前中国公益创业教育的研究内容分为公益创业教育的理论研究、公益创业教育的具体应用研究、公益创业教育与人才 培养的研究、公益创业教育课程资源开发的研究, 最后提出加大对公益创业教育理论的研究深度、丰富对公益创业教 育的研究领域、促进完整的公益创业教育课程体系的构建的促进中国公益创业教育的思考与建议, 以期有助于中国公 益创业教育的进一步发展与提高。

关键词: 公益创业教育, 现状, 启示, 内容分析法 


\section{1. 引言}

公益创业（Social Entrepreneurship）又被译为“公益创 新”、“社会创业”等, 最早起源于欧美发达国家, 应社会 需要而产生, 并在国外许多国家蓬勃发展 ${ }^{[1]}$ 。1998年法国 经济学家蒂埃里·让泰（Thierry）提出公益创业的概念, 哈佛大学格雷格·迪斯（Greg Dees）博士第一次将公益创 业课程搬进课堂。2002年英国政府开始推行“社会企业战 略”推动公益创业的发展 ${ }^{[2]}$ 。经过近三十年的发展, 英国、 美国等发达国家公益创业已经形成完整的产业链，成为社 会经济发展的重要组成部分。

在中国, 公益创业还处于起步阶段。上世纪末，政府 部门、社会福利机构、事业单位等在不同程度上承担起了 社会公益责任并不断寻求发展 ${ }^{[3]}$ 。进入 21 世纪, 随着中国 经济的飞速发展, 国家对创新型人才的需求不断加大, 这 就要求了各级各类教育单位对于人才的培养更加重视了 对学生的创新能力、社交能力、协调合作能力等综合素质 的培养。在指导政策方面, 2010年教育部下发《关于大力 推进高等学校创新创业教育和大学生自主创业工作的意 见》，2012年教育部又发布了《普通本科学校创业教育教 学基本要求(试行)》，2015年国务院办公厅下发了《关于 深化高等学校创新创业教育改革的实施意见》。因此, 在 国家多种政策的大力支持下, 公益创业作为一种新兴的创 业活动形式日益成为大学生创业的新趋势, 而公益创业教 育也随之应运而生, 并在各级各类学校得到发展。公益创 业教育自提出以来一直受到中国学者的广泛关注, 并在各 个领域也出现了相关的研究成果。本文以目前中国有关公 益创业教育研究成果为研究对象, 采用内容分析法对公益 创业教育研究在中国的发展进行深层次的解读, 试探讨公 益创业教育在中国的研究现状及启示。

\section{2. 研究设计}

\section{1. 研究方法与材料}

本研究样本为从中国知网 (CNKI) 检索到的期刊论 文。中国有关于公益创业教育的论文从 2008 年开始出现, 截至 2017 年 6 月, 在中国知网上以“公益创业教育”为检 索项, 调整检索条件为“主题”, 之后根据文献的关联程度, 剔除掉无关文献期刊后得到有效研究样本为 112 篇。

\section{2. 类目分析单元}

本文将公益创业教育在中国的研究成果从文献数量 分布、期刊分布情况、研究层次分析和文献研究内容分析 四个角度为研究维度, 根据样本文献的研究内容, 梳理总 结后将公益创业教育的研究内容分为以下四类主题:

[1] 林爱菊. 大学生公益创业的困境及对策探讨 [J]. 学理 论,2016,(12):96-98。

[2] 韦小双,关明.大学生公益创业教育的现实困境与实践路径 $[\mathrm{J}]$.金华职 业技术学院学报,2014,(1):8-11。

[3] 韦小双, 关明. 大学生公益创业教育的现实困境与实践路径 [J]. 金华 职业技术学院学报, 2014,(1):8-11。
(1) 公益创业教育的理论研究 探讨公益创业教育 的概念、起源、特质、现实意义等方面的探索;

(2) 公益创业教育的具体应用研究——探讨了将公益 创业教育应用于具体学科教学、各类公益项目、竞赛项目 等方面的研究;

(3) 公益创业教育与人才培养的研究——阐明公益创 业教育对于人才发展的作用, 涵盖公益创业教育模式的探 讨以及公益创业人才培养模式的探讨等内容;

(4) 公益创业教育课程资源开发的研究一一探讨了公 益创业教育课程的开发以及配套设施的建设研究。

\section{3. 公益创业教育在中国教育领域研究状况分析}

\section{1. 研究过程分析}

通过对文献的统计分析, 与公益创业教育相关学术论 文按年份分布的情况如图1所示。

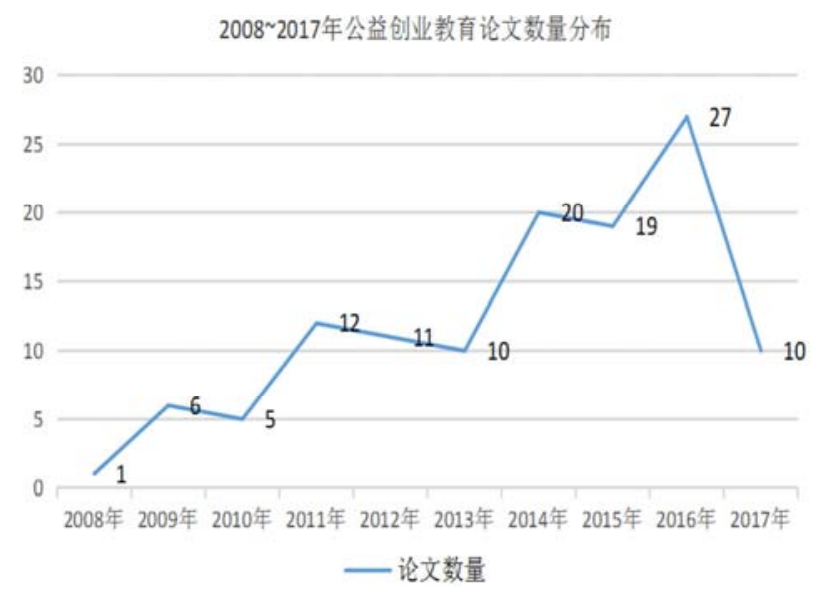

图1 公益创业教育文献期刊数量分布统计。

由图1可知, 2008到2010年间, 学者对这一领域已经 进行研究但文献数量较少, 且增长趋势不明显。2014年开 始则呈较明显的增长趋势, 仅2016年发表的文献数量已超 过 08 至 10 年文章的总数, 但总的来说, 中国对于公益创业 教育的研究还处于起步阶段, 随着政府和专家学者对公益 创业教育这一新兴领域的不断关注, 对公益创业教育的各 类研究也将逐渐深入。

\section{2. 期刊来源分析}

据笔者统计, 中国有关公益创业教育的研究期刊分布 于59种不同的期刊, 分布比较均匀且广泛。期刊发文量超 过2篇的有12种, 共30篇（占 $26.79 \%$ ）, 如表1所示。表1 还呈现了这些期刊的种类, 并将6种被核心类来源期刊收 录的文章以深色阴影表示 (16篇)。从广度上看, 发表的 论文期刊数虽然很多, 但在深度上看, 高质量的研究还相 对较少。进一步说, 现阶段中国学者对公益创业教育在教 育中的应用研究并不系统, 发文期刊比较分散, 且分布于 各个层次的期刊中, 多是对公益创业教育理论层面的探讨。 因此, 对公益创业教育在教育领域的研究, 应逐渐向更深 层次的思考、应用与实证研究方向上进行延伸与拓展。 
表1 样本期刊数量分布情况。

\begin{tabular}{llll}
\hline 期刊名 & 数量 & 期刊名 & 数量 \\
\hline 教育与职业 & 5 & 无锡商业职业技术学院学报 & 2 \\
黑龙江高教研究 & 3 & 中国商贸 & 2 \\
金融经济 & 3 & 学校党建与思想教育 & 2 \\
青年探索 & 3 & 企业导报 & 2 \\
继续教育研究 & 2 & 成才与就业 & 2 \\
大学教育科学 & 2 & 高教探索 & 2 \\
\hline
\end{tabular}

\section{3. 研究层次分析}

通过对文献的统计分析, 公益创业教育研究层次比 重分布的情况如图2所示。由图2可知, 基础研究类的文 献超过了一半的比例, 高达 $50.42 \%$, 行业指导类的文献 占了 $36.13 \%$, 而政策研究、职业指导等类的文献所占比 例较小, 说明当前对于公益创业教育的研究主要还是集 中于对此主题的起源、概念、特点、意义等基础原理的 探究。

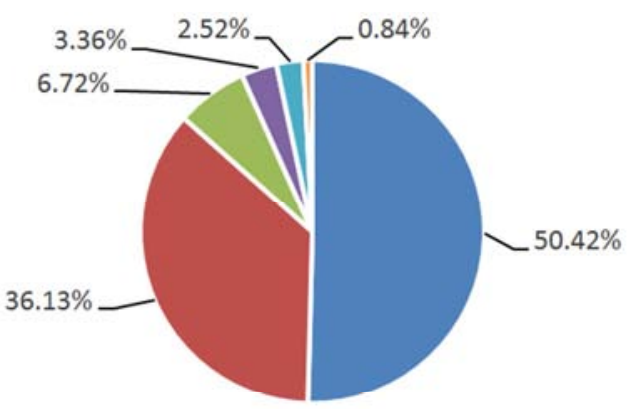

\section{- 基础研究 - 行业指导 $\mid$ 政策研究 \\ - 职业指导 $=$ 高等教育 $=$ 大众文化}

图2 各研究层次比重分布。

\section{4. 研究内容分析}

通过对样本文献的归纳分析可得各类目比重分布情 况: 关于公益创业教育的理论研究共 47 篇 $(41.97 \%)$ ，它 是目前中国研究的主要方向; 其次是关于公益创业教育与 人才培养的研究共 31 篇 $(27.78 \%)$; 关于公益创业教育的 具体应用研究共 21 篇 $(18.75 \%)$ ；关于公益创业教育课程 资源的开发研究共13篇（11.61\%），如图3所示。

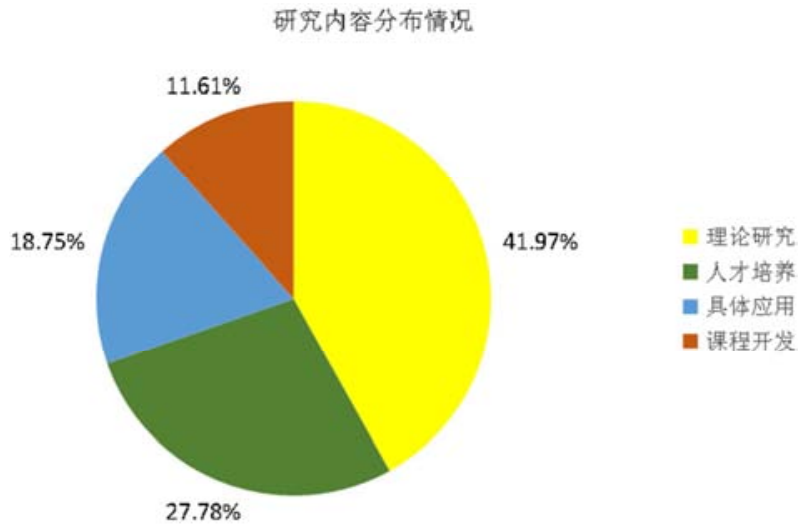

图3 各研究主题比重分布。

\section{4. 1. 公益创业教育的理论研究}

关于公益创业教育的理论研究比例最大, 表明该主题 是中国学者目前主要的研究方向。笔者将该部分的研究进 行归纳分析, 得出公益创业教育的理论研究主要集中于公 益创业教育的起源及概念的研究、公益创业教育意义及特 征的研究、公益创业教育的现状和发展路径探讨三个方面。 通过对文献的分析归纳可得出以下观点: (1)对公益创业教 育起源及概念的研究还停留在表面层次的总结和探讨阶 段, 且关于公益创业教育的定义目前处于各抒已见的状态, 需要权威机构对公益创业教育的标准定义做一个正式的 规定; (2)有关公益创业教育的意义及特征的文章还较少, 中国公益创业教育的研究时间还不长, 主要依据社会发展 需求以及国家政策引导进行探讨; (3)对公益创业教育的现 状和发展路径进行探讨的文章, 主要针对目前公益创业教 育发展过程中出现的问题以及对发展路径的设想和建议。

\subsection{2. 公益创业教育与人才培养的研究}

该部分的研究主要集中在研究高校公益创业教育的 培养目标、培养模式、公益创业教育体系等方面进行探讨。 通过对文献的归纳分析可得如下观点: (1)由于在高校中开 展公益创业教育处于起步阶段, 诸多问题均需进行更深入 的探讨, 对公益创业教育的培养目标定位、专业课程设置、 师资力量建设等都将成为研究重点; (2)在此部分有多篇文 章讨论了如何在高校培养公益创业教育人才, 说明了高校 相当重视培养高素质的公益创业教育人才, 但在普通高校 和高职高专院校建设公益创业教育的必要性与可行性的 探讨也需要重视; (3)为促进中国公益创业教育人才的培养, 除了高校要鼓励和支持学生有组织、有目标、可持续地开 展公益服务活动和项目之外, 还需要有一个包括政府、企 业、非营利组织在内的社会创业支持系统来支持高校公益 创业教育的发展。

\section{4.3. 公益创业教育的具体应用研究}

笔者通过对文献的归纳分析, 发现目前对于公益创业 教育的具体应用主要体现在高等教育中。公益创业教育的 具体应用研究主要集中于三个方面: (1)高校公益创业教育 专项计划和项目在高校的实施、发展以及建议等等, 且多 为试点型工作的归纳和总结。例如扬州大学"青苗计划"项 目, 充分利用了该校专业资源、依托班级社团建设、强化 品牌意识、借助历史传统及既有工作机制四方面入手总结 出大学生参与公益创投的路径 ${ }^{[4]}$; (2)公益创业教育与具体 学科教育的整合方面, 例如与思想政治教育的整合 ${ }^{[5]}$ 。公 益创业教育已经逐渐成为高校培养人才的重要内容, 而思 想政治教育一直都是高校教育的主要方面, 将二者进行有 机融合, 符合时代发展的需要。(3)把公益创业教育作为一 种平台促进大学生综合素质的发展。例如高校通过拓展公 益创业基地、与相关单位通力合作搭建公益创业平台, 让

[4] 印月.大学生参与公益创投的实践与思考——以扬州大学 “青苗计划” 项目为例 [J].安康学院学报,2016,(6):120-123。

[5] 周娜,李丹,哈福滔.公益创业教育融入高校思想政治教育研究[J].河北 企业,2016,(4):158-159。 
大学生通过参加公益创业活动, 能提高自身的各项能力, 加强自身的竞争优势 ${ }^{[6]}$ 。

\section{4. 4. 公益创业教育课程资源开发的研究}

关于公益创业教育课程资源开发的研究文献占全部 样本文献总数的 $11.61 \%$, 比例最小。尽管目前对公益创业 教育课程开发的研究呈现出增长的趋势, 但是通过对文献 的分析可以看出中国公益创业教育课程开发、课程资源建 设依旧处于探索阶段, 仍需不断地发展与完善。曾建国、 刘镇江 ${ }^{[7]}$ (2015) 提出以质量功能展开(QFD)理论来优化 设置公益创业教育课程, 李作战 ${ }^{[8]}$ (2009) 提出从大学生 创业中的能力和品质培养的视角出发去设计中国高校当 前的创业教育模式以及对课程进行优化设置。这些研究成 果对中国公益创业教育课程资源的建设具有重大的参考 价值, 对于公益创业教育课程开发与建设的探索也为教育 一线工作者提供了参考。这里需要注意的是, 公益创业教 育课程资源的开发不仅仅是要开发课程, 还应考虑到课程 的管理、培训、应用、评价等多个方面的工作。

\section{4. 思考与建议}

本文通过梳理和分析公益创业教育在中国的研究成 果, 总结了目前中国公益创业教育的研究内容与研究方向, 在此基础上提出以下思考与建议:

\section{1. 加大对公益创业教育理论的研究深度}

如前所述, 目前对公益创业教育的理论研究主要集中 于公益创业教育的起源及概念、意义及特征的研究、公益 创业教育的现状和发展路径探讨三个方面。尽管对于公益 创业教育的起源及概念的研究的数量不少, 但是对其定义 与本质的研究还不够深刻, 深度研究不够。主要体现在两 个方面: 一方面是目前中国对公益创业教育的理论研究, 主要都是综述性研究, 例如公益创业教育的起源与概念的 探讨。另一方面, 很多的研究都是对公益创业教育的现状 和发展路径进行概括和总结, 但对于发展路径的实施以及 其效果作用没有进行深入研究, 缺乏实证性。因此专家学 者应该加大对公益创业教育理论的研究深度, 不断地积极 构思考推动公益创业教育如何更科学、有效地发展，进而 推进学生综合素质的全面发展。

\section{2. 丰富对公益创业教育的研究领域}

从前文样本文献分析来看, 目前中国的研究主要集中 在理论研究、具体应用研究与人才培养方面的研究, 而对 公益创业教育课程资源的建设开发研究非常少。从样本文 献的结构来看, 中国公益创业教育的研究相对较分散、未 成体系, 并且研究领域的涉及面太窄, 还有很多可以发掘

[6] 曾淑文, 以公益创业为平台促进大学生成长成才研究[J].中国成人教 育, 2017,(2):81-83。

[7] 曾建国,刘镇江.基于 QFD 的高校公益创业教育课程设置优化研究 [J].继续教育研究, 2015,(3):134-135。

[8] 李作战,基于品质和能力培养的大学创业教育课程体系设计 [J].中国 电力教育, $2009,(8): 88-90$ 。
的新领域。但就目前来看, 由于中国公益创业教育的研究 起步较晚, 还处于探索阶段, 所以中国研究公益创业教育 的大多数研究成果主要还是围绕公益创业教育的概念和 起源、公益创业教育开设的必要性及意义等内容展开, 很 少将视野转到教学和实践中。因此, 丰富公益创业教育此 方面的研究势在必行, 同时也需要广大专家和学者们钻研 和实践。

\section{3. 促进完整的公益创业教育课程体系的构建}

从目前中国公益创业教育研究的情况来看, 不管是普 通在高校还是中小学, 公益创业教育都没有形成一套完整 的课程体系。但随着公益创业教育在学校教育领域中的不 断运用和发展, 其课程体系建构会逐渐产生和完善。首先, 公益创业教育课程的设置也要根据教学环境、对象和资源 进行合理规划, 并做到从做中学、新颖有趣。从细处看, 还应增加公益创业教育课程与具体学科课程的整合, 注意 结合两者的优点, 打造更加个性化、创造性的公益创业教 育课程。其次, 要注意学生的个别差异性, 做到因材施教。 开发公益创业教育课程时, 应包含难度不同的由低到高的 一系列课程, 针对不同年级的学习对象, 开设符合其年龄 阶段的可接受难度的公益创业教育课程, 做到因材施教。 最后, 建设公益创业教育的课程体系还需设置统一的课程 标准和配套的正规公益创业教育教材, 公益创业教育课程 的管理、运用、培训和评价等配套工作也是必不可少的。

\section{5. 结论}

总的来说, 公益创业教育的研究在中国仍处于起步阶 段, 无论是理论研究还应用研究, 都有很大的探索空间, 尤其是在课程建设领域和人才培养领域以及其他新兴领 域还需要更多的专家学者予以重视, 不断挖掘和发展公益 创业教育在各个领域的巨大潜力和价值, 才能使公益创业 教育从一个舶来品, 逐渐融入到各个领域的实践中, 才能 真正在中国“落地生根”。这个融入的过程必定不是一帆风 顺的, 仍然还有许多问题和困难需要解决, 例如如何组织 公益创业教育活动, 推广公益创业文化, 以及如何做好顶 层规划设计, 实现可持续的发展等都是丞待解决的重大课 题, 仍需要很多的有识之士来攻坚克难, 共同推动公益创 业教育取得更长远的发展。

\section{参考文献}

[1] 林爱菊. 大学生公益创业的困境及对策探讨 [J]. 学理论, 2016,(12):96-98。

[2] 韦小双, 关明. 大学生公益创业教育的现实困境与实践路 径[J]. 金华职业技术学院学报, 2014,(1):8-11。

[3] 韦小双, 关明. 大学生公益创业教育的现实困境与实践路 径[J]. 金华职业技术学院学报, 2014,(1):8-11。

[4] 印月. 大学生参与公益创投的实践与思考一以扬州大学 “青苗计划”项目为例 [J]. 安康学院学报, 2016,(6):120-123。 
[5] 周娜, 李丹, 哈福滔. 公益创业教育融入高校思想政治教 育研究 [J]. 河北企业, 2016,(4):158-159。

[6] 曾淑文, 以公益创业为平台促进大学生成长成才研究 $[\mathrm{J}]$. 中 国成人教育，2017,(2):81-83。

[7] 曾建国, 刘镇江. 基于QFD的高校公益创业教育课程设置 优化研究 $[J]$. 继续教育研究, 2015,(3):134-135。

[8] 李作战, 基于品质和能力培养的大学创业教育课程体系设 计 $[\mathrm{J}]$. 中国电力教育, 2009,(8):88-90。

[9] 黄菲娅, 章程. 中国大学生公益创业发展现状研究 $[\mathrm{J}]$. 中 国校外教育，2014,(12):175-176。
[10] 张亿全, 徐佳. 高校大学生创业教育研究综述 $[\mathrm{J}]$. 中国电 力教育, 2011,(16):9。

[11] 梅士伟, 赵俊芳. 中国高校创业教育研究的热点、进展与 知识基础的图谱分析 [J]. 现代教育科学, 2017,(5):143-150。

[12] 曾德明, 汪忠等. 高校公益创业教育与创新人才培养探索 [J]．金融经济，2016,(5):18。

[13] 许明, 岳德虎. 高职学生公益创业的现状与发展趋势研究 [J]. 教育现代化, 2017,(13):29-31。

[14] 王迪. 大学生公益创业教育存在的问题及对策 $[\mathrm{J}]$. 教育与 职业，2016,(15):72-74。 